of electromagnetic machines, despite the duality which exists between them. There is no doubt that the shortage of technology on this subject is retarding the advance of the electrostatic machines. Nevertheless, an impressive array of standard machines were described, and on a subsequent visit to the factory of Société Anonyme de Machines Électrostatiques in Grenoble the members of the colloquium were able to see the ideas of Prof. Felici in concrete form. From the smallest machines for electrostatic deposition of paint to the large $600-\mathrm{kV}$. and $\mathrm{I}-\mathrm{MeV}$. generators for accelerators and other nuclear applications, one cannot help but be impressed by the progress of this technique. When it is realized that the continuous operation of these generators for thousands of hours with negligible maintenance is regarded as commonplace, an appreciation of the status of the technique is possible.

Of particular interest on the nuclear side were the neutron generators capable of delivering fluxes of neutrons up to $10^{11}$ neutrons per sec. Continuous development aimed at greater fluxes with smaller machines is being carried out.

To sum up, the position of the electrostatic generators at the present time is not easy. Both the French and American experts expressed faith that the present machines are the first in a field capable of great development. Discussion gave glimpses of actual development models in course of construction at the present time. Whether certain fundamental difficulties will obstruct this advance or whether new techniques will emerge remains to be seen. What. ever happens, great resources of money and labour will have to be made available.

The remainder of the lectures dealt with the applications of electrostatic machines. Two very interesting papers were read, one by Dr. W. D. Allen (Atomic Energy Research Establishment, Harwell) and the other by Mr. F. A. Julian (Atomic Weapons Research Establishment, Aldermaston). They described the remarkable achievements of the staff of the United Kingdom Atomic Energy Authority in constructing two $12 \mathrm{MeV}$. tandem accelerators which have now been in operation for the past year. The many problems which they encountered and overcame were discussed and a résumé of the experimental work carried out, both in the design of the machines and their subsequent usage, were given.
In the more commercial field of precipitation and mineral separation, the use of electrostatic generators has, as yet, had little application apart from the deposition of paint. Demonstrations of the paint precipitation plant show the fascinating possibilities of electrostatic machines in industry. The $100-\mathrm{kV}$. unit is very small, approximately $24 \mathrm{in}$. long, $9 \mathrm{in}$. wide and $9 \mathrm{in.} \mathrm{high,} \mathrm{and} \mathrm{completely} \mathrm{safe.} \mathrm{The} \mathrm{operator}$ may place his finger on the high-voltage terminal of the spray gun and feel very little effect. The generator is very light and easily portable. Being sealed in a high-pressure cylinder, it is impervious to all dirt and damp.

For other heavier precipitation processes, the electrostatic machine, so far, does not yet deliver sufficient current. Considerable research is going on in the United States in mineral separation. and, in Europe, on insecticidal spraying in agriculture.

Future applications in the nuclear field would appear to lie with neutron sources of higher fluxes than at present available. If fluxes of the order of $10^{12}-10^{14}$ neutrons per sec. could be produced economically, there would be a demand from those at present forced to use reactors for activation experiments. There is some argument as to what an economic figure might be, but there is a real hope that for an accelerator working at, say, $1 \mathrm{MeV}$., $4 \mathrm{~m}$.amp. of ions in the beam of a beryllium target could produce a flux of $10^{12}$ neutrons per sec. From preliminary inspection it was severally agreed that the price of such a machine might be very attractive vis-à-vis a small reactor. A $1-\mathrm{MeV}$. accelerator and a highcurrent ion-source of this type was shown to the members of the colloquium.

Both Prof. Trump and Prof. Felici touched on the possibility of power generation by electrostatic means. It may seem inconceivable that the electromagnetic power generators could be superseded by electrostatic methods for the generation of electric power for the grid system. However, a strong plea by Prof. Felici for research funds to be made available throughout the world for work in this direction was made. Prof. Felici cited the considerable advances achieved so far in the U.S.S.R., and the United States. Perhaps the domination of the present technology has blinded engineers to the possibilities in this other field.

\title{
BRITISH BOOKS AND PERIODICALS FOR USE OVERSEAS
}

$\mathrm{N}$ a written answer to questions in the House of Commons on November 7 about Government Information Services, the Chancellor of the Duchy of Lancaster, Dr. C. Hill, made a long statement about the low-priced book scheme. The first group of 23 text-books on scientific, engineering and other technological subjects, he said, is now being produced, and the books should be available during the forthcoming buying season to students and others in India at $9 s, 12 s$. or $15 s$. a volume, depending on size, diagrams, illustrations, otc. It was expected to discuss shortly with the Pakistan authorities the possibility of operating a similar scheme for that country.

Dr. Hill gave a list of the titles which had been approved by the Advisory Committee, following consultation with the university authorities in India. The list involved more than 100,000 volumes and more copies would be produced as necessary. A further group of university text-books on these and other subjects would follow. The Advisory Committee has also recornmended further categories of books, similarly aimed at helping to meet tho needs of readers in developing countries in Asia and Africa. One group of titles included would help people in these countries who wished to develop their knowledge of English, or to oxtend their practical skills, and those volumes would be available in substantially larger numbers and at much lower prices than the university text-books. The Advisory Committeo recognizes that some of its other recommendations involve books which need bringing up to date or 
other adaptation and that this work requires detailed and expert study. The Publishers' Association has now recommended to its membership the establishment of a consortium of publishers familiar with the export fields concerned or otherwise interested in the low-priced book scheme, which would pool the experience and resources of the trade in Britain and, in co-operation with local trade interests overseas, might further assist the Government's programme.

Dr. Hill also stated that an encouraging increase in the flow of British publications into Yugoslavia has occurred since the agreement with the Yugoslav Government was announced on April 14, and that the text of an agreement with the Israeli Government, providing for imports up to $£ 400,000$ a year of British books, periodicals, newspapers and certain kinds of gramophone records, was laid before the House on October 25. The Government of Indonesia is considering British proposals for an agreement to facilitate the import of British publications, and steps have been taken to overcome the difficulty arising from the system of import control used in Chile, which has led to an unsatisfied demand there for British books. The British Council has undertaken a considerable extension of its library services, and of the half-million books distributed by the Council in the past 18 months to its own libraries or other institutions all over the world, by far the greatest number have gone to Africa and Asia, especially to India, Pakistan and Ceylon. The range of learned periodicals covered by these libraries has also been greatly extended and many more presentations have been made to institutions such as medical schools.

In India and Pakistan, the Council's multiple holdings of widely used text-books has been very greatly increased, and in the past four months some 45 Indian universities and colleges have begun to use this scheme; the Council's services in these countries have also been improved by recruitment of a number of professional librarians to advise locally on the choice and direction of material and to organize the reference use of the libraries. Important presentations of books and periodicals have been made to colleges and other institutions in Nigeria, Coylon, Burma, Viet Nam, Malaya and Indonesia.

\section{THE POST OFFICE RESEARCH STATION}

COME of the scientific and engineering work of the $\checkmark$ Post Office Research Station at Dollis Hill, London, was shown during its open days, September 22-23. This Research Station serves the telephone and radio systems of the British Post Office, and also works on the mechanization of the postal service.

The Post Office (in collaboration with the National Physical Laboratory and the Royal Observatory) broadcasts signals of standard time-interval and frequency, having precisions of the order of \pm 2 parts in $10^{10}$. This has required the production of quartz crystals of great precision and stability, and the development of techniques for mounting them and maintaining them in oscillation at constant temperature. Further improvement in these time and frequency standards may require the use of cæsiumbeam resonators, one of which was shown working.

Transmission along wave-guides at frequencies such as 35,000 Mc./s. is a possible method of long. distance communication. The intended mode of transmission is $H_{01}$; all others must be suppressed since they have different velocities of propagation. Suppression can be achieved either by using for the wave-guide a close-wound helix, so that its longitudinal resistance is high, or by internal coating of a solid guide with a dielectric other than air. The first of these methods is being investigated by other workers; the Post Office is studying the use of dielectric coatings.

Parametric amplifiers operate through the variation of the electrical magnitude of some component by means of a local source of power - the 'pump'. They are particularly useful at frequencies greater than about $200 \mathrm{Mc} . / \mathrm{s}$. A parametric amplifier was shown working, based on a variable-capacitance diode, and suitable for a tropospheric-scatter system working at about $900 \mathrm{Mc} . / \mathrm{s}$.; a similar amplifier, for 960 Mc./s., had been used to receive signals from the United States by way of the balloon satellite Echo $I$.
For some years the Post Office has specialized in work on metallic magnetic materials. Samples of silicon-iron were shown in which special crystalline textures had been produced by suitable rolling and heat treatment. Methods shown for work on magnetic properties included measurement of saturation flux by reversal of the specimen itself in a stationary field-a method suggested by Ewing and apparently overlooked since his time-and an apparatus displaying the variation of magnetization with direction in anisotropic material.

For many purposes the Post Office is introducing transistors into its apparatus, but, as its need for reliability is unusually strict, it is interested in the probable life of transistors and in the causes of their premature failure. One investigation of this kind has led to the detection of leakage through seals, even when the leakage-rate is of the order of $10^{-11}$ litre micron per second. Improvements in thermionic valves are still being pursued, however, and gains in both performance and reliability have been achieved : a valve suitable for submarino cable systems, having a conductance of $25 \mathrm{~mA}$./V., yet operating at only $40-50 \mathrm{~V}$. high tension, has been produced by winding both control grid and screen grid on a single former.

The chemical laboratories have produced a range of organic phosphors, intended for making code markings in postal sorting work. They are based on cyanuric-acid-formaldehyde condensation compounds, and offer a wide range of colours. They are easily handled and can be incorporated into printing inks and other such media.

The influence of high-speed computers as an aid to physical and engineering research was clearly in evidence. Although the Research Station has no computer of its own, it hires time on other computers and has its own staff who can prepare computer programmes.
A. C. $\mathrm{LYNCH}_{\mathrm{Y}}$ 